\title{
The Dopamine Transporter in Mesencephalic Cultures Is Refractory to Physiological Changes in Membrane Voltage
}

\author{
Balakrishna M. Prasad and Susan G. Amara \\ Howard Hughes Medical Institute and Vollum Institute, Oregon Health Sciences University, Portland, Oregon 97201
}

The dopamine transporter (DAT) plays a crucial role in the clearance of extracellular dopamine in brain. Uptake of dopamine by the cloned human DAT has been shown to be electrogenic and voltage-dependent, with greater uptake observed at hyperpolarized potentials. Ventral mesencephalic dopaminergic neurons were used to assess the kinetics of dopamine uptake in relation to their electrical activity. Dopamine uptake in these cultures was saturable with a $K_{\mathrm{m}}$ of $\sim 560 \pm 60 \mathrm{~nm}$ and a DAT turnover rate of $0.74 \pm 0.07$ dopamine molecules per second. The effects of physiological changes in membrane voltage on transporter function were assessed by the activation of G-protein-coupled receptors. Current-clamp recordings of dopamine neurons showed that dopamine, baclofen, and or- phanin FQ (OFQ) cause varying degrees of hyperpolarization. However, dopamine uptake was not affected by the activation of $D_{2}, G A B A_{B}$, or OFQ receptors. Dopamine neurons in culture fired spontaneous action potentials at an average frequency of 2.3 Hz. Thus, dopamine neurons fire approximately three action potentials in the time taken for DAT to go through one transport cycle. Application of tetrodotoxin $(1 \mu \mathrm{M})$ blocked action potentials but did not alter the uptake of dopamine. These data demonstrate that DAT turnover is a relatively slow process and the rate-limiting step for transport cycle is insensitive to changes in membrane voltage in physiological range.

Key words: dopamine; transporter; voltage; $D_{2}$ receptor; $G A B A_{B}$ receptor; orphanin $F Q$
Dopaminergic transmission in brain forms a critical part of neural circuitry involved in reward system and goal-oriented behavior. Activity of midbrain dopaminergic neurons is altered by emotionally relevant environmental stimuli (Schultz, 2000; Woodward et al., 2000) and translates into increased extracellular concentration of dopamine that persists from a few seconds to several minutes (Richardson and Gratton, 1996; Dominguez et al., 2001). High frequency activation of dopamine neurons that resembles their burst-firing pattern is more efficient at increasing extracellular dopamine compared with low-frequency stimulation (Gonon, 1988; Garris and Wightman, 1994). Saturation of the dopamine uptake process (Chergui et al., 1994) and enhanced dopamine release per stimulus (Manley et al., 1992) have been proposed to be the possible mechanisms for the augmented dopamine levels that are observed during high-frequency activation of dopamine neurons. However, the relationship between dopamine uptake kinetics and neuronal activity has not been directly measured.

The dopamine transporter (DAT) plays an important role in the clearance of extracellular dopamine and is a target for psychoactive drugs involved in drug abuse and pharmacotherapy of certain mental illnesses. Substrate translocation by DAT and structurally related norepinephrine (NET) and serotonin (SERT) transporters is associated with inward currents (Mager et al., 1994; Galli et al., 1995; Sonders et al., 1997). Because uptake is electrogenic, it was postulated that membrane voltage might influence the kinetics of this process, but direct evidence for voltage

Received May 16, 2001; revised July 12, 2001; accepted July 18, 2001.

This work is supported by the National Institute of Drug Abuse Grant DA07595 (S.G.A.) and the Howard Hughes Medical Institute (S.G.A.). We thank Susan Ingram for her assistance in electrophysiological recording, Lori Vaskalis for help with illustrations, and members of the Amara laboratory for helpful comments on this manuscript.

Correspondence should be addressed to Dr. Susan G. Amara, 3181 SW Sam Jackson Park Road, L474, Portland, OR 97201. E-mail: amaras@ohsu.edu.

Copyright (C) 2001 Society for Neuroscience $0270-6474 / 01 / 217561-07 \$ 15.00 / 0$ regulation of uptake by monoamine transporters in the CNS is equivocal. Uptake by DAT and transport-associated currents of NET are moderately voltage-dependent, changing approximately twofold with a $100 \mathrm{mV}$ change in membrane potential (Sonders et al., 1997; Galli et al., 1998). Substrate translocation by Drosophila SERT (Galli et al., 1997), but not rat SERT (Mager et al., 1994), was altered by changes in membrane potential, demonstrating a species difference in voltage dependence for this presynaptic neuronal transporter. The physiological significance of voltagedependent monoamine uptake is unclear because these observations were made in electrically quiescent cells, whereas the presynaptic transporters in brain encounter rapid changes in membrane potential.

Activity of DAT has been shown to be affected by $\mathrm{D}_{2}$ receptors because their antagonists decrease the clearance of exogenous dopamine in vivo and in striatal homogenates in vitro (Meiergerd et al., 1993; Cass and Gerhardt, 1994). The mechanism underlying this regulation is not clear, with different reports suggesting $D_{2}$ receptor-mediated hyperpolarization or signal transduction mechanisms as possible mediators (Hoffman et al., 1999; Mayfield and Zahniser, 2001). However, dopamine uptake by PC12 cells was not influenced by $\mathrm{D}_{2}$ receptor activity (Pothos et al., 1998), indicating that cellular environment influences the regulation of DAT.

The primary goals of this work are to relate kinetics of dopamine uptake to the electrical activity of neurons and to test the effect of physiological changes in membrane potential on DAT activity in its native environment. In addition, the putative role of three of the G-protein-coupled receptors, including dopamine $\mathrm{D}_{2}$ receptors, in the modulation of DAT function was evaluated in ventral mesencephalic primary cultures.

\section{MATERIALS AND METHODS}

Materials. Ketamine $\mathrm{HCl}$ was purchased from Fort Dodge Laboratories (Fort Dodge, IA), and papain was from Worthington Biochemicals (Lakewood, NJ). All other chemicals, unless stated otherwise, were from 
Sigma (St. Louis, MO). Synthetic orphanin FQ (OFQ) was a generous gift of Dr. David K. Grandy (Oregon Health Sciences University, Portland, OR). Glial medium consisted of minimum essential medium (Life Technologies, Grand Island, NY) with $10 \%$ heat-inactivated fetal bovine serum, $0.45 \%$ D-glucose, $5 \mathrm{pg} / \mathrm{ml}$ insulin, $0.5 \mathrm{~mm}$ glutamine, $100 \mathrm{U} / \mathrm{ml}$ penicillin, and $100 \mu \mathrm{g} / \mathrm{ml}$ streptomycin. Neuronal medium is composed of $50 \%$ minimum essential medium, 39\% Ham's-F12 medium, $10 \%$ heatinactivated horse serum, $1 \%$ heat-inactivated fetal bovine serum, $0.45 \%$ D-glucose, $5 \mathrm{pg} / \mathrm{ml}$ insulin, and $0.1 \mathrm{mg} / \mathrm{ml}$ apotransferrin. Ringer's solution used for uptake and binding is composed of (in mM): $124 \mathrm{NaCl}, 15$ $\mathrm{Na}_{2} \mathrm{HPO}_{4}, 2.8 \mathrm{KCl}, 1.2 \mathrm{MgSO}_{4}, 1 \mathrm{CaCl}_{2}, 10 \mathrm{D}$-glucose, and 1 ascorbic acid, $\mathrm{pH}$ 7.4.

Cell culture. Ventral mesencephalic cells, including dopamine neurons from substantia nigra and ventral tegmental area, were cultured as described by Rayport et al. (1992), with a few modifications. Sprague Dawley rat pups (2 to 4-d-old) were anesthetized with the intraperitoneal injection of ketamine $\mathrm{HCl}$ (3 $\mathrm{mg}$ per pup). Ventral midbrains were dissected and incubated in a dissociation medium containing $20 \mathrm{U} / \mathrm{ml}$ papain at $34-36^{\circ} \mathrm{C}$ under continuous oxygenation for $2 \mathrm{hr}$. Then, the tissue was triturated with fire-polished Pasteur pipette in glial medium. Dissociated cells were pelleted by centrifugation at $500 \times g$ for $10 \mathrm{~min}$ and resuspended in glial medium. Cells were plated in 48 -well tissue culture dishes that were coated with $100 \mu \mathrm{g} / \mathrm{ml}$ poly-D-lysine and $5 \mu \mathrm{g} / \mathrm{ml}$ laminin at a density of $\sim 150,000$ cells per well. We found that minimizing the delay in plating of cells intended for different treatments was essential to avoid variability in transport measurements. One hour after plating, the medium was changed to neuronal medium that was conditioned overnight on cultured cortical glia. The conditioned neuronal medium was supplemented with $1 \mathrm{ng} / \mathrm{ml}$ glial cell line-derived neurotrophic factor and $500 \mu \mathrm{M}$ kynurenate and filter-sterilized, before it was added to mesencephalic cultures. For electrophysiological recording, mesencephalic cells were cultured on $12 \mathrm{~mm}$ round glass coverslips coated with poly-D-lysine and laminin.

Synaptosomal preparation. Striatal tissue from adult male Wistar rats was used for the preparation of crude synaptosomes. Tissue was homogenized in 10 volumes of $0.32 \mathrm{~m}$ sucrose solution and centrifuged at $1,700 \times g$ for $10 \mathrm{~min}$. Supernatant free of nuclei and debris was pelleted at $21,200 \times g$ for $20 \mathrm{~min}$. This second pellet (P2) was resuspended in Ringer's solution.

Uptake and binding assays. Uptake of ${ }^{3} \mathrm{H}$-dopamine was typically performed for $2 \mathrm{~min}$ at room temperature. Mesencephalic cells that were cultured for $13 \mathrm{~d}$ in vitro were washed twice with Ringer's solution, and varying concentrations of ${ }^{3} \mathrm{H}$-dopamine (with or without different test drugs) were added to the cells. For saturation analyses of uptake, five different dopamine concentrations ranging from 0.05-4.05 $\mu \mathrm{M}$ were used with only $10 \%$ of the total dopamine being tritiated. Uptake was terminated with two washes of ice-cold Ringer's solution, and radioactivity from cells was extracted into $3 \%$ trichloroacetic acid for $30 \mathrm{~min}$. Binding of ${ }^{125}$ IRTI-55 was performed using a similar protocol at $4^{\circ} \mathrm{C}$ for $1 \mathrm{hr}$. RTI-55 concentration ranged from $0.01-6.25 \mathrm{nM}$, with $100 \%$ of tracer being radiolabeled. Nonspecific uptake and binding were determined in the presence of GBR12909 $(10 \mu \mathrm{M})$.

Uptake of $50 \mathrm{~nm}{ }^{3} \mathrm{H}$-dopamine in synaptosomes was performed in a total volume of $500 \mu \mathrm{l}$ for $2 \mathrm{~min}$. Receptor antagonists were preincubated with synaptosomes for $4-5 \mathrm{~min}$, whereas receptor agonists were added 30 sec before the addition of labeled dopamine. Uptake was terminated by the addition of $5 \mathrm{ml}$ of cold Ringer's solution, and the synaptosomes were harvested onto Whatman filter paper using Brandel cell harvester. After two additional washes, radioactivity that was collected on filter paper was counted with liquid scintillation analyzer.

Electrophysiology. Cells cultured on glass coverslips for 10-16 d in vitro were used to determine the effects of receptor agonists and antagonists. The external solution used for the majority of the recordings was comprised of (in mM): $130 \mathrm{NaCl}, 5 \mathrm{HEPES}, 3 \mathrm{KCl}, 1.2 \mathrm{MgCl}_{2}, 2.5 \mathrm{CaCl}_{2}$, and 30 D-glucose. The remainder of recordings were performed in Ringer's solution. No significant difference was observed in resting membrane potential, action potential frequency, or the receptor-induced changes in membrane potential between recordings obtained with the two external buffers. The composition of the internal solution was (in mM): 128 K-gluconate, $10 \mathrm{KCl}, 10 \mathrm{HEPES}, 1 \mathrm{MgCl}_{2}, 0.3 \mathrm{CaCl}_{2}, 1$ EGTA, $2 \mathrm{ATP}$, $0.2 \mathrm{GTP}$, and $0.03 \%$ biocytin, $\mathrm{pH}$ 7.4. Current-clamp (Iclamp-normal) recordings were performed with Axopatch-200B amplifier (Axon Instruments, Foster City, CA). Whole-cell configuration of recording was established with electrodes that had 2-5 M $\Omega$ resistance in bath solution. Effects on membrane voltage were assessed after bath application of

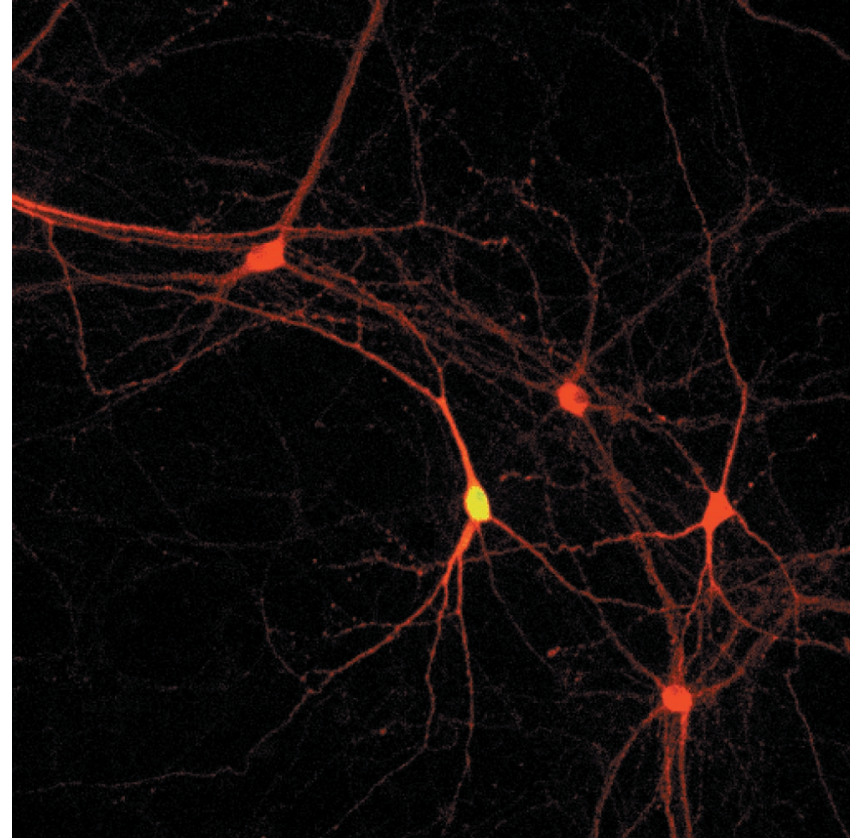

Figure 1. A representative TH-immunoreactive neuron that was filled with biocytin during electrophysiological recording. Red represents TH, and biocytin is labeled with Oregon Green.

different drugs. Membrane voltage data collected at $10 \mathrm{kHz}$ was filtered with low-pass Bessel filter at $2 \mathrm{kHz}$ and digitized with Digidata 1200. Continuous voltage traces were recorded using the Chart program (v3.6; ADInstruments, Castle Hill, New South Wales, Australia) and analyzed offline after correcting for an estimated junction potential of $15.4 \mathrm{mV}$ between internal and bath solutions.

Immunostaining. Immediately after electrophysiological recording, the cells were fixed with $4 \%$ paraformadehyde in PBS for $15 \mathrm{~min}$ at room temperature. The coverslips were washed twice in PBS and stored at $4^{\circ} \mathrm{C}$. Immunostaining procedure was started with 30 min incubation in PBS containing $4 \%$ normal horse serum, $1 \%$ bovine serum albumin, and $0.2 \%$ Triton X-100. The antibodies were diluted in PBS containing $0.25 \%$ bovine serum albumin and $0.2 \%$ Triton X-100. Mouse monoclonal antityrosine hydroxylase (TH) antibody (clone $\mathrm{TH}-16$; Sigma) was used at a dilution of 1:1500 to identify dopaminergic neurons. Rhodamine Red-X conjugated donkey anti-mouse antiserum $(8 \mu \mathrm{g} / \mathrm{ml}$; Jackson ImmunoResearch, West Grove, PA) and streptavidin Oregon Green $(3 \mu \mathrm{g} / \mathrm{ml}$; Molecular Probes, Eugene, OR) were used to visualize TH and biocytin, respectively. A confocal laser-scanning microscope was used with appropriate excitation and emission filter setup to identify $\mathrm{TH}$ staining in biocytin-filled cells. All electrophysiological data presented are from neurons confirmed to be TH-immunoreactive (Fig. 1).

Data analysis. Uptake and binding data were analyzed with KaleidaGraph (Synergy Software, Reading, PA) to determine affinity constants and maximal responses. Turnover rate of DAT (DA molecules per second) was calculated by dividing the $V_{\max }$ expressed as femtomoles of dopamine per second per well by the $B_{\max }$ expressed as femtomoles of RTI-55 binding sites per well. $V_{\max }$ gives the quantity of substrate translocated in a given time with the transporters maximally saturated, whereas $B_{\max }$ represents the total number of transporter molecules expressed at the cell surface. This calculation assumes that each RTI-55 binding site reflects a functional DAT molecule. Because dopamine uptake by DAT follows Michaelis-Menten kinetics, the data were analyzed using the equation $V=V_{\max } \cdot[\mathrm{DA}] /\left(K_{\mathrm{m}}+[\mathrm{DA}]\right)$, where $V$ is velocity of uptake at a given concentration of dopamine [DA], $V_{\max }$ is the maximal velocity, and $K_{\mathrm{m}}$ is the apparent affinity of dopamine to the transporter. RTI-55 binding was analyzed by the equation $B=B_{\max }$. $[\mathrm{RTI}-55] /\left(K_{\mathrm{d}}+[\mathrm{RTI}-55]\right)$, where $B$ is the binding at a given concentration of ligand [RTI-55], $B_{\max }$ is the maximal binding, and $K_{\mathrm{d}}$ is the dissociation constant.

Membrane potential and action potential frequencies were analyzed on Chart program. Membrane potential before and during drug application was measured by averaging all the data points (including those 


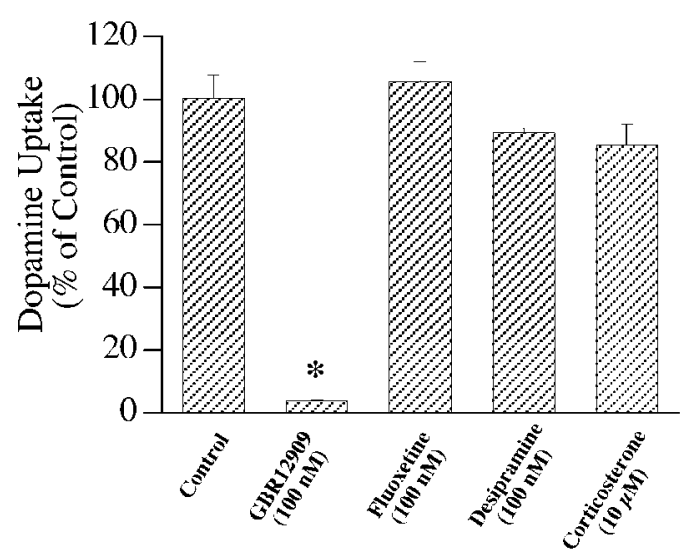

Figure 2. Pharmacological sensitivity of dopamine uptake in mesencephalic cultures. Uptake of $50 \mathrm{~nm}{ }^{3} \mathrm{H}$-dopamine in primary cultures in presence of different inhibitors is presented. Data from quadruplicate observations in a single experiment are normalized to control group and expressed as mean \pm SEM. * indicates a significant difference from control $(p<0.01$; Student's $t$ test). Similar effects of inhibitors were observed in independent experiments ( $n=2$; data not shown).

during action potentials and after hyperpolarizations) during respective periods. These data were analyzed with paired Student's $t$ test. Bursts of action potentials were identified by analyzing spikes with Axograph 4.0. Each action potential event was identified by a $10 \mathrm{mV} / \mathrm{msec}$ increase in membrane potential. Onset of a burst was defined with an interspike interval of $<80 \mathrm{msec}$ and termination of burst by an interval $>160 \mathrm{msec}$ (Grace and Bunney, 1984b). Only cells that showed at least two bursts of three spikes each during a 2 min analysis period were classified as burst firing. Frequencies of action potentials in identified bursts were also analyzed with Axograph 4.0.

\section{RESULTS}

\section{Dopamine uptake by DAT in mesencephalic primary cultures is slow}

Uptake of ${ }^{3} \mathrm{H}$-dopamine in ventral mesencephalic cultures is potently inhibited by the DAT selective blocker GBR 12909, but was not sensitive to fluoxetine, desipramine, or corticosterone, the selective inhibitors of serotonin, norepinephrine, and organic cation transporters, respectively (Fig. 2). Uptake of dopamine at the highest concentration used in saturation analysis $(4.05 \mu \mathrm{M})$ was linear for $4 \mathrm{~min}$ (data not shown), and 2 min uptake was performed for all of the saturation experiments. The uptake occurred with a $K_{\mathrm{m}}$ of $560 \pm 60 \mathrm{~nm}$ for dopamine (Fig. $3 A$ ), a value similar to that observed in synaptosomal preparations (Krueger, 1990). These data confirm that dopamine uptake in primary cultures is mediated by DAT. To determine the turnover rate of DAT, ${ }^{3} \mathrm{H}$-dopamine uptake and ${ }^{125} \mathrm{I}$-RTI55 binding were performed in parallel cultures. RTI-55 binding data with five ligand concentrations were best fit to a single binding site with a $K_{\mathrm{d}}$ of $1.8 \pm 0.5 \mathrm{~nm}$ (Fig. $3 B$ ). $V_{\max } / B_{\max }$ values calculated per well were $0.74 \pm 0.07$ per second, indicating that each DAT molecule requires $\sim 1.35 \mathrm{sec}$ to go through a transport cycle (assuming that each RTI-55 binding site represents a single functional DAT molecule).

\section{Membrane potential and dopamine uptake}

The Xenopus oocyte expression system has been the method of choice to assess the effect of membrane potential on uptake by transporters. This system has the advantage of allowing direct measurement of uptake into a cell that is held under voltage clamp. However, monitoring of radioactive substrate uptake in single neurons under voltage clamp has not been achieved to date.
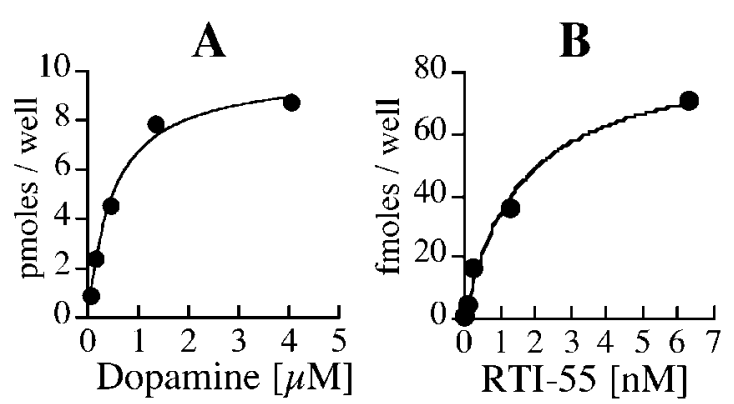

Figure 3. Saturation analysis of dopamine uptake and RTI-55 binding in primary cultures. Representative data of dopamine uptake $(A)$ and RTI-55 binding $(B)$ obtained in parallel cultures are presented. Data are averages of duplicate observations. The $V_{\max }$ of dopamine uptake is 10 $\mathrm{pmol} /$ well for $2 \mathrm{~min}$, and the $B_{\max }$ of RTI- 55 binding is $88 \mathrm{fmol} /$ well. The DAT turnover rate calculated from this experiment is $0.95 / \mathrm{sec}(83.3 / 88$ fmol per second), with an average of $0.74 \pm 0.07 / \mathrm{sec}$ from four independent experiments. Affinity of RTI-55 binding in cultures is $1.8 \pm 0.5 \mathrm{nM}$. A total of nine independent experiments (including those used for turnover rate estimation and control groups from subsequent experiments) were used to determine $K_{\mathrm{m}}$ of dopamine uptake at $560 \pm 60 \mathrm{nM}$.

Thus, we used receptor agonists and antagonists that alter membrane voltage to assess the rate of uptake under "pharmacological voltage clamp."

Dopamine neurons contain $\mathrm{D}_{2}$ autoreceptors that cause hyperpolarization of these neurons in vivo and in vitro. Current-clamp recordings in dopaminergic neurons showed that dopamine (4 or $10 \mu \mathrm{M}$ ) hyperpolarizes dopamine neurons by $5.3 \mathrm{mV}$ (Fig. $4 A, B$, Table 1). This effect was blocked by $\mathrm{D}_{2}$ receptor antagonists raclopride or sulpiride. Quinpirole $(1 \mu \mathrm{M})$, a $\mathrm{D}_{2}$-selective agonist also produced a hyperpolarization similar in magnitude to that of dopamine (data not shown). When ${ }^{3} \mathrm{H}$-dopamine is added to the cultures, it not only serves as a substrate for DAT but also can activate $\mathrm{D}_{2}$ receptors present on dopaminergic neurons. In fact, the higher concentrations of ${ }^{3} \mathrm{H}$-dopamine used for determining the kinetics of transport are also sufficient to activate the maximal $\mathrm{D}_{2}$ receptor-mediated response (Fig. 4) (Werner et al., 1996). However, the presence of raclopride $(10 \mu \mathrm{M})$ or sulpiride $(10 \mu \mathrm{M})$ at concentrations that block the hyperpolarizing effect of dopamine did not alter either the apparent affinity or maximal velocity of dopamine uptake (Fig. $4 C$ ).

Because the effect of $\mathrm{D}_{2}$ receptor activation on membrane potential is modest, agonists for two other G-protein-coupled receptors $\left(\mathrm{GABA}_{\mathrm{B}}\right.$ and $\mathrm{OFQ}$ receptors) were used to alter membrane potential. It is well established that activation of $\mathrm{GABA}_{\mathrm{B}}$ receptors causes a pronounced hyperpolarization in dopaminergic neurons in vivo as well as in vitro (Lacey et al., 1988; Engberg et al., 1993). Activation of $\mathrm{GABA}_{\mathrm{B}}$ receptors with baclofen (10 $\mu \mathrm{M})$ caused an average of $19.1 \mathrm{mV}$ hyperpolarization in dopaminergic neurons (Fig. $5 A$, Table 1 ). The effect of baclofen was immediately reversed after washout of the drug. OFQ is a neuropeptide that is involved in a wide array of functions, including nociception, locomotor activity, and drug abuse (Ciccocioppo et al., 2000; Reinscheid et al., 2000). OFQ receptors are expressed in several different brain regions (Mollereau and Mouledous, 2000) and, like the $D_{2}$ and $\mathrm{GABA}_{\mathrm{B}}$ receptors, are coupled to the activation of inwardly rectifying potassium channels (Matthes et al., 1996). Activation of OFQ receptors on cultured dopaminergic neurons with synthetic OFQ $(1 \mu \mathrm{M})$ caused a marked hyperpolarization with an average magnitude of $18.6 \mathrm{mV}$, but in contrast to baclofen, its effects persisted even after drug washout (Fig. $5 B$, 

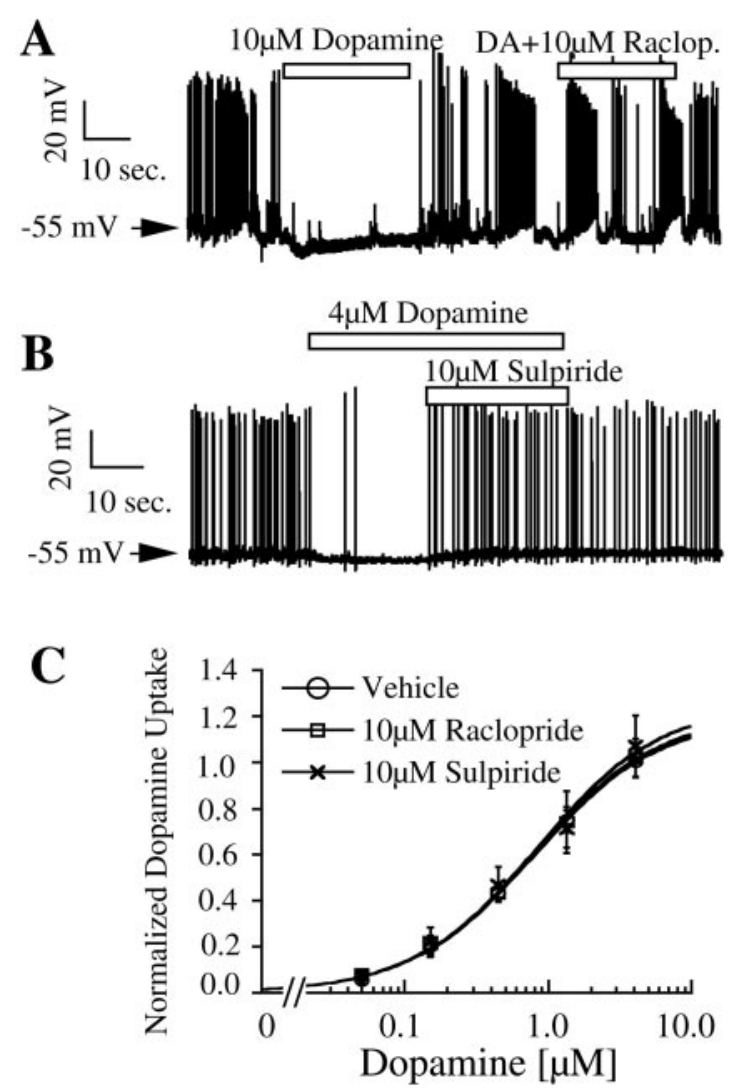

Figure 4. Effect of dopamine and $\mathrm{D}_{2}$ antagonists on membrane voltage and dopamine uptake in neurons. Representative membrane voltage traces demonstrating the effect of dopamine, raclopride $(A)$, and sulpiride $(B)$ on dopamine neurons are presented. Statistical analysis of this and other electrophysiological data is presented in Table 1. $C$, Uptake data from three independent experiments at different concentrations of substrate are presented as mean \pm SEM. Data from duplicate observations within each experiment are normalized to uptake at $4.05 \mu \mathrm{M}$ dopamine concentration in control cultures.

Table 1). Neither baclofen $(10 \mu \mathrm{M})$ nor OFQ $(1 \mu \mathrm{M})$ altered dopamine uptake in cultures compared with that of vehicletreated controls (Fig. 5C). Because the vehicle-treated cells are subject to $\mathrm{D}_{2}$ receptor activation and because dopamine does not further enhance the magnitude of hyperpolarization in baclofen and OFQ-treated cells (data not shown), the actual membrane potential difference between control and baclofen- or OFQtreated cells is $\sim 14 \mathrm{mV}$ (Table 1). However, uptake saturation curves generated in the presence of $\mathrm{D}_{2}$ receptor antagonists, baclofen, or OFQ were virtually identical in experiments in which a direct comparison was made $(n=2)$. These results, together with the lack of effect of $\mathrm{D}_{2}$ receptor activity on dopamine uptake, lead us to conclude that a $19 \mathrm{mV}$ hyperpolarization does not significantly alter dopamine uptake in neurons.

To confirm the lack of effect of G-protein-coupled receptor activation in a different native expression system, DAT-mediated uptake was measured in striatal synaptosomes. Dopamine uptake in synaptosomes was confirmed to be attributable to DAT because it was sensitive to GBR12909 (100 nM), whereas desipramine and citalopram were ineffective even at $1 \mu \mathrm{M}$ concentration (data not shown). Uptake of $100 \mathrm{~nm}$ dopamine in synaptosomes was not affected by raclopride $(10 \mu \mathrm{M})$, sulpiride $(10 \mu \mathrm{M})$, quinpirole $(1 \mu \mathrm{M})$, baclofen $(10 \mu \mathrm{M})$, or OFQ $(1 \mu \mathrm{M})$ (Fig. 6). Striatal synaptosomes that were used in this study are likely to contain
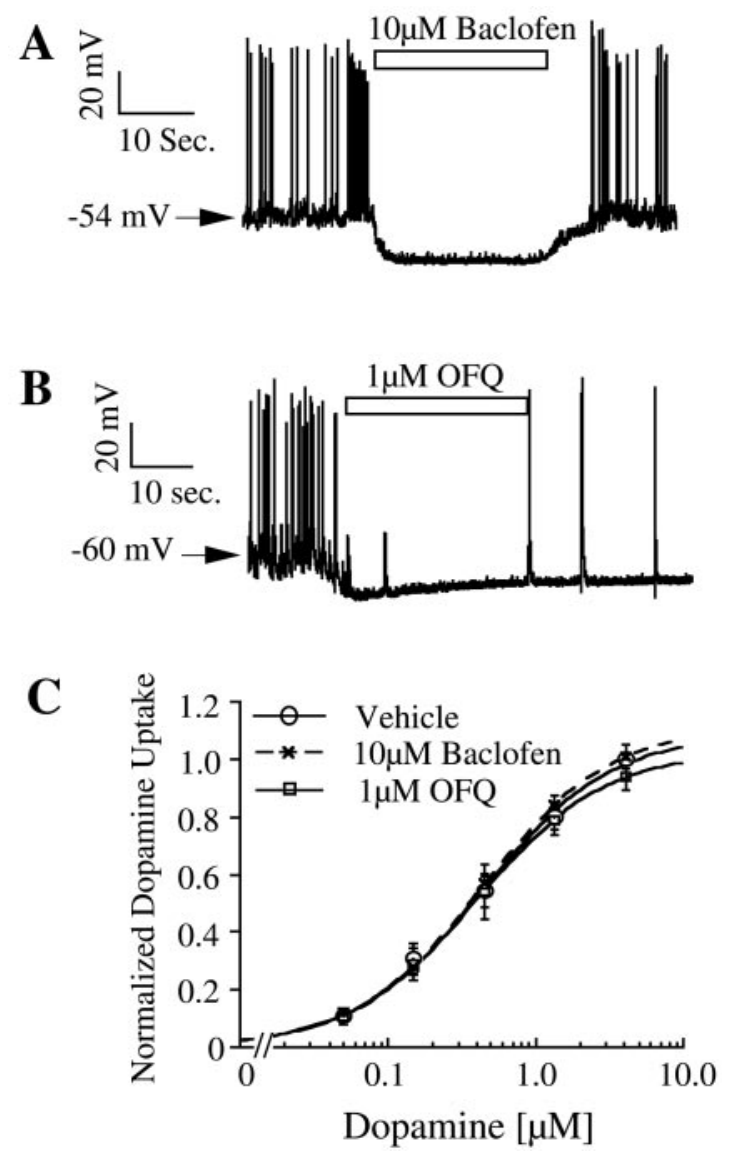

Figure 5. Effect of $\mathrm{GABA}_{\mathrm{B}}$ receptor agonist baclofen $(A)$ and OFQ $(B)$ on membrane potential and dopamine uptake $(n=3)(C)$ in primary cultures.

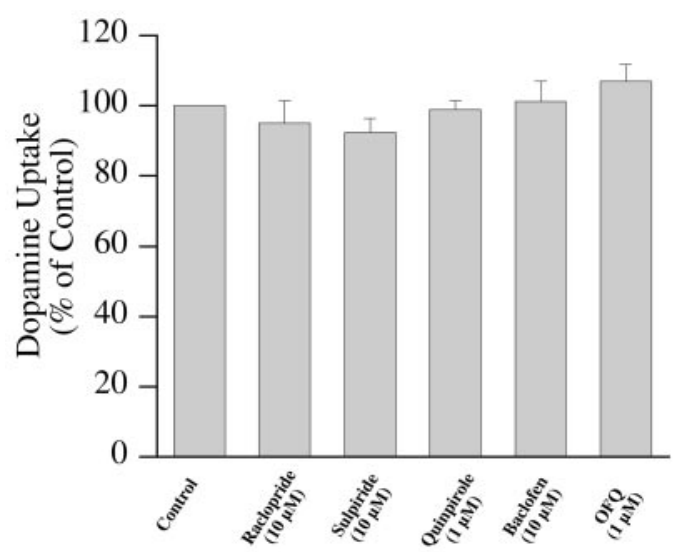

Figure 6. Effect of G-protein-coupled receptor activation on dopamine uptake in striatal synaptosomes. Uptake of $100 \mathrm{~nm}{ }^{3} \mathrm{H}$-dopamine into synaptosomes in presence of different compounds is shown. Normalized data from three independent experiments are presented as mean \pm SEM.

functional $\mathrm{D}_{2}, \mathrm{GABA}_{\mathrm{B}}$, and $\mathrm{OFQ}$ receptors, although this was not directly confirmed. There is anatomical and physiological evidence for the existence of $\mathrm{D}_{2}, \mathrm{GABA}_{\mathrm{B}}$, and $\mathrm{OFQ}$ receptors on presynaptic nerve terminals (Sesack et al., 1994; Misgeld et al., 1995; Meis and Pape, 2001). Both $\mathrm{D}_{2}$ and $\mathrm{GABA}_{\mathrm{B}}$ receptors have been shown to be functional in striatal synaptosomes that were obtained using similar protocols as the one used in this study (Yi 
A

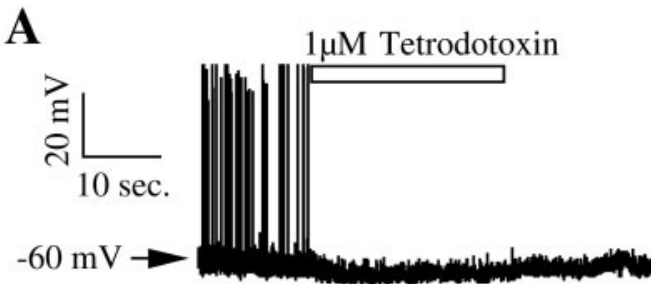

B



C

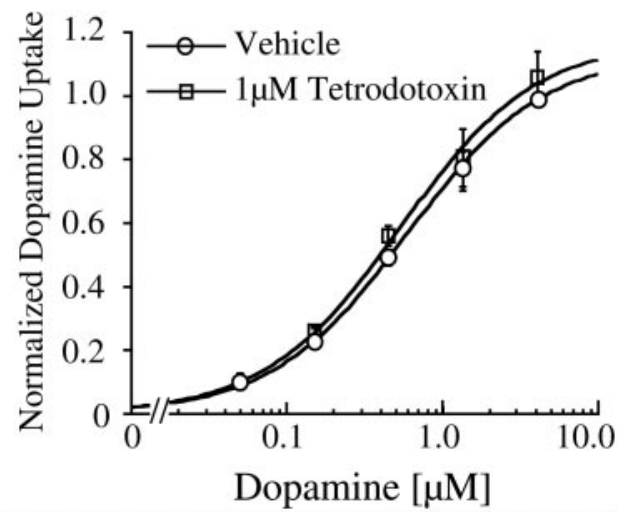

Figure 7. Effect of tetrodotoxin on dopamine neuronal firing $(A)$ and dopamine uptake $(n=3)(C)$. B, Voltage trace of a dopamine neuron with expanded time scale shows an action potential burst with four spikes.

and Johnson, 1990; Zoltay and Cooper, 1994). These data reinforce the observations made in cultures by addressing receptormediated effects on DAT in dopamine neuronal terminals derived from adult rats of a different strain from those used for cultures.

\section{Neuronal firing and dopamine uptake}

Analysis of voltage recordings from 20 dopamine neurons in vitro showed that they fire spontaneous action potentials at a rate of $2.3 \pm 0.22 \mathrm{~Hz}$. Sixteen of 20 neurons showed burst firing based on the criterion outlined in Materials and Methods. Bursting activity is clearly noticeable during recovery from OFQ (Fig. 4B) and with an expanded time scale (Fig. 7B). Each burst contained two to six action potentials with the firing frequency during individual bursts ranging from $10-50 \mathrm{~Hz}$, with an average of $17 \pm 1.6 \mathrm{~Hz}$. Perfusion of $1 \mu \mathrm{M}$ tetrodotoxin completely abolished the firing of action potentials and bursting activity (Fig. $7 A ; n=3$ ). However, inhibition of action potentials by tetrodotoxin did not affect dopamine uptake (Fig. 7B). Thus, neither hyperpolarization nor transient depolarization caused by action potentials altered kinetics of dopamine uptake in mesencephalic cultures.

\section{DISCUSSION}

Electrophysiological properties of dopamine neurons and the regulation of dopamine transporter by membrane voltage and signal transduction mechanisms have been studied extensively. Surprisingly, the function of DAT in relation to the electrical activity of dopamine neurons, in which this transporter is ex-

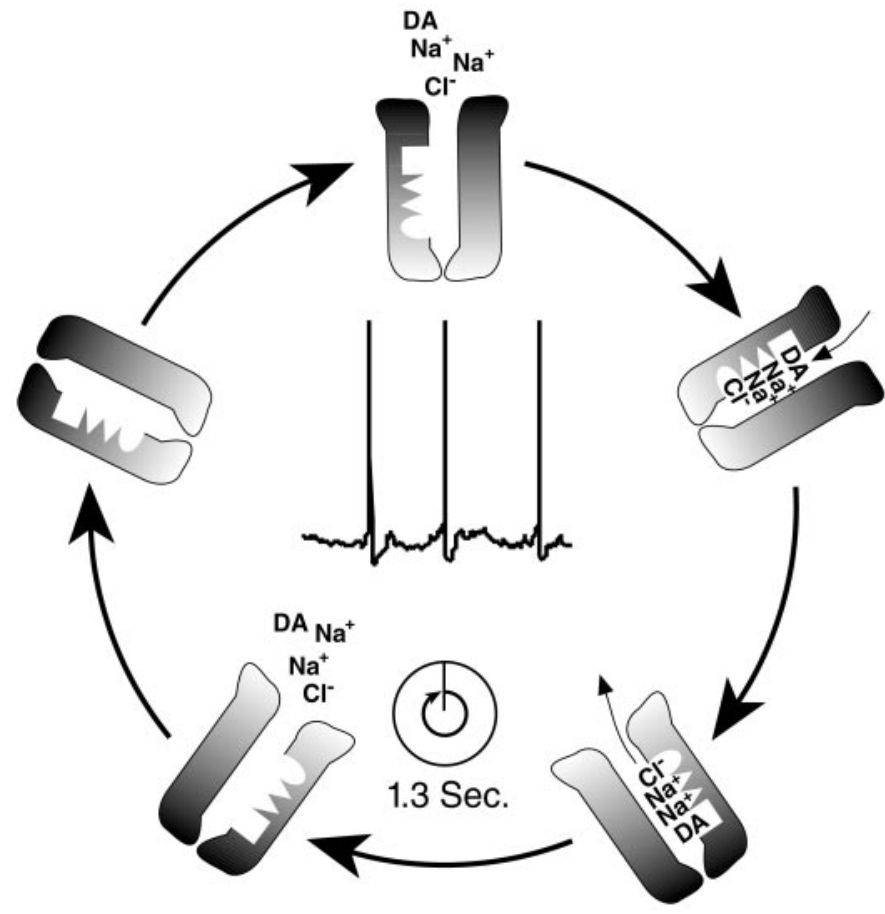

Figure 8. Voltage trace of a dopamine neuron and a diagram depicting the dopamine transporter cycle. Dark shading of the DAT represents its extracellular surface, and translocation of cosubstrates from extracellular space to inside the cell is depicted. The illustration shows that an average of three action potentials are fired by dopamine neuron during the $1.3 \mathrm{sec}$ needed for DAT turnover.

pressed, has not been investigated. This is the first demonstration of uptake kinetics of DAT in the context of electrical activity of dopamine neurons. Uptake of dopamine by DAT in cultured neurons occurs with an apparent affinity of $560 \mathrm{nM}$ and a turnover rate of 0.74 per second. This turnover rate is slow compared with the average action potential firing rate of $2.3 \mathrm{~Hz}$ in dopamine neurons. The uptake function of DAT appears to be shielded from the influence of action potentials and changes in membrane voltage caused by G-protein-coupled receptor activation. These data also show that the second messenger systems activated by these receptors were unable to modulate uptake under the conditions used in this study.

Dopaminergic neurons in vivo fire action potentials in regular spiking or burst-firing modes. The action potential bursts have a spike frequency of $15 \mathrm{~Hz}$, whereas regular spiking occurs at a frequency of $5 \mathrm{~Hz}$ (Grace and Bunney, 1984a,b; Freeman and Bunney, 1987). Increase in extracellular dopamine concentration during burst activation of dopamine neurons is greater than that observed after the same number of stimuli at lower frequency. Because temporal summation does not account for all of the enhanced release during a burst, saturation of dopamine uptake process or enhanced release of dopamine have been proposed as possible mechanisms underlying this phenomenon (Manley et al., 1992; Chergui et al., 1994). Direct measurement of DAT turnover rate in neurons showed that it is a relatively slow process with three action potentials being fired during one transport cycle (Fig. 8 ), indicating that saturation of DAT activity might contribute to the increased efficiency of burst firing. The frequency of action potentials relative to the DAT turnover number is likely to be similar in cultures at $24^{\circ} \mathrm{C}$ and in vivo at $37^{\circ} \mathrm{C}$. In additional experiments, we have shown that the turnover number for DAT is 


\begin{tabular}{|c|c|c|c|c|c|}
\hline Drug & Before & During drug & Change & $p$ value & Number \\
\hline Dopamine $(4$ or $10 \mu \mathrm{M})$ & $-54.9 \pm 1.0$ & $-60.1 \pm 1.6$ & $-5.2^{*}$ & $<0.001$ & 17 \\
\hline $\mathrm{DA}+\mathrm{D}_{2}$ antagonist & $-54.8 \pm 2.3$ & $-53.9 \pm 2.1$ & 0.9 & 0.47 & 6 \\
\hline Baclofen $(10 \mu \mathrm{M})$ & $-57.8 \pm 3.2$ & $-76.9 \pm 3.2$ & $-19.1^{*}$ & $<0.001$ & 7 \\
\hline Orphanin FQ $(1 \mu \mathrm{M})$ & $-56.1 \pm 2.5$ & $-74.6 \pm 1.9$ & $-18.6^{*}$ & $<0.001$ & 9 \\
\hline
\end{tabular}

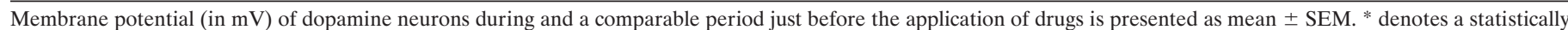
significant change in voltage analyzed with a paired Student's $t$ test. The $p$ value and number of cells used for each drug are shown in the last two columns.

2.3-fold higher at $37^{\circ} \mathrm{C}$ than at room temperature, resulting in a cycle time of $0.57 \mathrm{sec}$ (data not shown). Based on an in vivo neuronal firing rate of $5 \mathrm{~Hz}$, there will be $\sim 2.8$ action potentials per transport cycle at $37^{\circ} \mathrm{C}$, with this number being even greater during burst-firing mode. In addition to the data on turnover rates provided here, other critical information regarding DAT density, subcellular distribution, and basal occupancy, as well as the kinetics of dopamine diffusion, will be required for a more complete picture of the dynamic regulation of extracellular dopamine concentrations.

Ventral mesencephalic primary cultures are a good expression system for the study of dopamine transporter in its native intracellular environment. Several different observations in this and previous studies show that the electrical properties and cell surface receptor expression of dopamine neurons in culture are similar to those in vivo. The resting membrane potential, spontaneous firing, action potential duration, presence of hyperpolarization-activated current, and bursting activity of neurons are similar in cultured neurons and those in vivo (Grace and Bunney, 1984a,b; Cardozo, 1993). The G-protein-coupled dopamine $\mathrm{D}_{2}, \mathrm{GABA}_{\mathrm{B}}$, and OFQ receptors that are expressed on dopamine neurons in vivo are also expressed in vitro. The hyperpolarizing actions of $\mathrm{D}_{2}$ and $\mathrm{GABA}_{\mathrm{B}}$ receptors on dopamine neurons have been well established in vivo as well as in vitro (Chiodo et al., 1984; Lacey et al., 1988; Cardozo, 1993). Similar to its effect on cultured cells, OFQ has a potent hyperpolarizing effect on dopamine neurons in mesencephalic slices (D. K. Grandy, personal communication). The long-lasting effect of OFQ on dopamine neurons in vitro suggests that this peptide may play an important role in the physiology of mesencephalic dopaminergic system. In addition to maintaining the major physiological and neurochemical hallmarks of dopaminergic neurons, the neuronal cultures transport dopamine with similar apparent affinity and ion dependency to those observed in a variety of different brain preparations. Thus, the apparent insensitivity of dopamine transporter to the physiological voltage changes and receptor activity in cultures is likely to represent its characteristics in vivo. Conservation of electrical properties, signal transduction mechanisms, and maintenance of ionic gradients required for uptake make culture systems more reliable for the study of transporter function than synaptosomes or other in vitro systems. Indeed, we observed that the DAT turnover rate estimated in synaptosomes was $\sim 10$-fold lower than that in cultures (B. M. Prasad, unpublished observation), indicating the presence of either RTI-55 binding sites that do not catalyze transport or transporters that operate less efficiently in synaptosomes.

Agents that alter membrane potential have been shown to affect uptake by dopamine transporter in synaptosomes (Holz and Coyle, 1974; Krueger, 1990). Because the manipulations (ion replacements and ionophores) that were used in these studies alter the ion gradients required for transporter function, the direct contribution of membrane potential to the changes observed is unclear. Effect of membrane potential on uptake was assessed under voltage clamp in Xenopus oocytes expressing human DAT (hDAT). Uptake of dopamine at $-120 \mathrm{mV}$ was $85 \%$ greater than that at $-30 \mathrm{mV}$, whereas transport-associated currents were on average $200 \%$ higher for the same change in voltage (Sonders et al., 1997). The effect of membrane potential on dopamine uptake but not on transporter currents showed marked variation between oocyte batches. The inability of hyperpolarization (caused by receptor agonists) to change dopamine uptake in mesencephalic cultures is consistent with the shallow and variable voltage dependence of hDAT observed in oocytes. A $19 \mathrm{mV}$ shift in membrane potential did not alter dopamine uptake by rat DAT (rDAT) because its function may be modestly voltage dependent. Alternatively, it is likely that uptake by rDAT is not affected by voltage as observed for rat SERT (rSERT) in oocytes. Regardless of any possible effect of extreme voltages on rDAT function, uptake is not altered by changes in membrane potential that occur in a physiological context.

A lack of $\mathrm{D}_{2}$ receptor modulation of DAT function observed in this study is consistent with the failure of $\mathrm{D}_{2}$ receptor activity to alter dopamine uptake in PC12 cells (Pothos et al., 1998). These data are in contrast to previous studies that have implicated $D_{2}$ dopamine receptor as a physiological regulator of DAT (Meiergerd et al., 1993; Cass and Gerhardt, 1994). The reason for this discrepancy is unclear, but assay method and experimental system used to assess DAT function may be responsible for the differences. In general, the experiments that support $\mathrm{D}_{2}$ receptor modulation of DAT function used clearance of exogenously applied dopamine as a measure of uptake. Some studies showed that the clearance rate of dopamine was decreased by $\mathrm{D}_{2}$ antagonists (Meiergerd et al., 1993; Rothblat and Schneider, 1997; Hoffman et al., 1999), whereas others demonstrated a change in amplitude of dopamine signal without altering the clearance rate (Cass and Gerhardt, 1994; Dickinson et al., 1999). Haloperidol but not clozapine changed dopamine clearance rate in striatum, whereas neither antagonist affected the amplitude of dopamine signal (Rothblat and Schneider, 1997). These reports emphasize the variability associated with different pharmacological agents and the clearance parameters being studied with voltammetry. A voltage-independent G-protein-mediated increase in surface expression of hDAT was postulated based on observations in Xenopus oocytes co-expressing DAT and $\mathrm{D}_{2}$ receptors (Mayfield and Zahniser, 2001). $\mathrm{D}_{2}$ antagonists altered radiolabeled dopamine uptake only in oocytes that had low DAT expression but not in cells that expressed DAT more abundantly. The failure of DAT regulation by $D_{2}$ receptors in mesencephalic cultures and striatal synaptosomes may be analogous to the lack of $\mathrm{D}_{2}$ regulation seen in oocytes that show high DAT expression.

Data presented in this manuscript suggest that the uptake kinetics of dopamine are not affected by membrane voltage or 
signal transduction mechanisms after $\mathrm{D}_{2}, \mathrm{GABA}_{\mathrm{B}}$, or OFQ receptor activation. Because dopamine neurons cultured in vitro mimic the properties of those in vivo and provide a way to unambiguously analyze the kinetics of dopamine uptake, it likely that these observations represent in vivo properties of DAT. We propose that the activity of $\mathrm{D}_{2}, \mathrm{GABA}_{\mathrm{B}}$, and $\mathrm{OFQ}$ receptors modulates neurotransmission via changes in the synaptic release of dopamine rather than its clearance. Slow turnover rate of DAT relative to neuronal firing suggests that voltage independence of DAT is advantageous for dopamine clearance and that saturation of uptake process may contribute to the increased dopamine signaling during burst firing.

\section{REFERENCES}

Cardozo DL (1993) Midbrain dopaminergic neurons from postnatal rat in long-term primary culture. Neuroscience 56:409-421.

Cass WA, Gerhardt GA (1994) Direct in vivo evidence that $\mathrm{D}_{2}$ dopamine receptors can modulate dopamine uptake. Neurosci Lett 176:259-263.

Chergui K, Suaud-Chagny MF, Gonon F (1994) Nonlinear relationship between impulse flow, dopamine release and dopamine elimination in the rat brain in vivo. Neuroscience 62:641-645.

Chiodo LA, Bannon MJ, Grace AA, Roth RH, Bunney BS (1984) Evidence for the absence of impulse-regulating somatodendritic and synthesis-modulating nerve terminal autoreceptors on subpopulations of mesocortical dopamine neurons. Neuroscience 12:1-16.

Ciccocioppo R, Angeletti S, Panocka I, Massi M (2000) Nociceptin/ orphanin FQ and drugs of abuse. Peptides 21:1071-1080.

Dickinson SD, Sabeti J, Larson GA, Giardina K, Rubinstein M, Kelly MA, Grandy DK, Low MJ, Gerhardt GA, Zahniser NR (1999) Dopamine $D_{2}$ receptor-deficient mice exhibit decreased dopamine transporter function but no changes in dopamine release in dorsal striatum. J Neurochem 72:148-156.

Dominguez J, Riolo JV, Xu Z, Hull EM (2001) Regulation by the medial amygdala of copulation and medial preoptic dopamine release. J Neurosci 21:349-355.

Engberg G, Kling-Petersen T, Nissbrandt H (1993) GABAB-receptor activation alters the firing pattern of dopamine neurons in the rat substantia nigra. Synapse 15:229-238.

Freeman AS, Bunney BS (1987) Activity of A9 and A10 dopaminergic neurons in unrestrained rats: further characterization and effects of apomorphine and cholecystokinin. Brain Res 405:46-55.

Galli A, DeFelice LJ, Duke BJ, Moore KR, Blakely RD (1995) Sodiumdependent norepinephrine-induced currents in norepinephrinetransporter-transfected HEK-293 cells blocked by cocaine and antidepressants. J Exp Biol 198:2197-2212.

Galli A, Petersen CI, deBlaquiere M, Blakely RD, DeFelice LJ (1997) Drosophila serotonin transporters have voltage-dependent uptake coupled to a serotonin-gated ion channel. J Neurosci 17:3401-3411.

Galli A, Blakely RD, DeFelice LJ (1998) Patch-clamp and amperometric recordings from norepinephrine transporters: channel activity and voltage-dependent uptake. Proc Natl Acad Sci USA 95:13260-13265.

Garris PA, Wightman RM (1994) Different kinetics govern dopaminergic transmission in the amygdala, prefrontal cortex, and striatum: an in vivo voltametric study. J Neurosci 14:442-450.

Gonon FG (1988) Nonlinear relationship between impulse flow and dopamine released by rat midbrain dopaminergic neurons as studied by in vivo electrochemistry. Neuroscience 24:19-28.

Grace AA, Bunney BS (1984a) The control of firing pattern in nigral dopamine neurons: single spike firing. J Neurosci 4:2866-2876.

Grace AA, Bunney BS (1984b) The control of firing pattern in nigral dopamine neurons: burst firing. J Neurosci 4:2877-2890.

Hoffman AF, Zahniser NR, Lupica CR, Gerhardt GA (1999) Voltagedependency of the dopamine transporter in the rat substantia nigra. Neurosci Lett 260:105-108.
Holz RW, Coyle JT (1974) The effects of various salts, temperature and alkaloids veratridine and batrachotoxin on the uptake of $\left[{ }^{3} \mathrm{H}\right]$ dopamine into synaptosomes from rat striatum. Mol Pharmacol 10:746-758.

Krueger BK (1990) Kinetics and block of dopamine uptake in synaptosomes from rat caudate nucleus. J Neurochem 55:260-267.

Lacey MG, Mercuri NB, North RA (1988) On the potassium conductance increase activated by $\mathrm{GABA}_{\mathrm{B}}$ and dopamine $\mathrm{D}_{2}$ receptors in rat substantia nigra neurones. J Physiol (Lond) 401:437-453.

Mager S, Min C, Henry DJ, Chavkin C, Hoffman BJ, Davidson N, Lester HA (1994) Conducting states of a mammalian serotonin transporter. Neuron 12:845-859.

Manley LD, Kuczenski R, Segal DS, Young SJ, Groves PM (1992) Effects of frequency and pattern of medial forebrain bundle stimulation on caudate dialysate dopamine and serotonin. J Neurochem 58:1491-1498.

Matthes H, Seward EP, Kieffer B, North RA (1996) Functional selectivity of orphanin FQ for its receptor coexpressed with potassium channel subunits in Xenopus laevis oocytes. Mol Pharmacol 50:447-450.

Mayfield RD, Zahniser NR (2001) Dopamine $\mathrm{D}_{2}$ receptor regulation of the dopamine transporter expressed in Xenopus laevis oocytes is voltage-independent. Mol Pharmacol 59:113-121.

Meiergerd SM, Patterson TA, Schenk JO (1993) $\mathrm{D}_{2}$ receptors may modulate the function of the striatal transporter for dopamine: kinetic evidence from studies in vitro and in vivo. J Neurochem 61:764-767.

Meis S, Pape HC (2001) Control of glutamate and GABA release by nociceptin/orphanin FQ in the rat lateral amygdala. J Physiol (Lond) 532:701-712.

Misgeld U, Bijak M, Jarolimek W (1995) A physiological role for GABAB receptors and the effects of baclofen in the mammalian central nervous system. Prog Neurobiol 46:423-462.

Mollereau C, Mouledous L (2000) Tissue distribution of the opioid receptor-like (ORL1) receptor. Peptides 21:907-917.

Pothos EN, Przedborski S, Davila V, Schmitz Y, Sulzer D (1998) $D_{2}$-like dopamine autoreceptor activation reduces quantal size in PC12 cells. J Neurosci 18:5575-5585.

Rayport S, Sulzer D, Shi WX, Sawasdikosol S, Monaco J, Batson D, Rajendran G (1992) Identified postnatal mesolimbic dopamine neurons in culture: morphology and electrophysiology. J Neurosci 12:4264-4280.

Reinscheid RK, Nothacker H, Civelli O (2000) The orphanin FQ/nociceptin gene: structure, tissue distribution of expression and functional implications obtained from knockout mice. Peptides 21:901-906.

Richardson NR, Gratton A (1996) Behavior-relevant changes in nucleus accumbens dopamine transmission elicited by food reinforcement: an electrochemical study in rat. J Neurosci 16:8160-8169.

Rothblat DS, Schneider JS (1997) Regionally specific effects of haloperidol and clozapine on dopamine reuptake in the striatum. Neurosci Lett 228:119-122.

Schultz W (2000) Multiple reward signals in the brain. Nat Rev Neurosci 1:199-207.

Sesack SR, Aoki C, Pickel VM (1994) Ultrastructural localization of D2 receptor-like immunoreactivity in midbrain dopamine neurons and their striatal targets. J Neurosci 14:88-106.

Sonders MS, Zhu SJ, Zahniser NR, Kavanaugh MP, Amara SG (1997) Multiple ionic conductances of the human dopamine transporter: the actions of dopamine and psychostimulants. J Neurosci 17:960-974.

Werner P, Hussy N, Buell G, Jones KA, North RA (1996) D2, D3, and $\mathrm{D} 4$ dopamine receptors couple to $\mathrm{G}$ protein-regulated potassium channels in Xenopus oocytes. Mol Pharmacol 49:656-661.

Woodward DJ, Chang JY, Janak P, Azarov A, Anstrom K (2000) Activity patterns in mesolimbic regions in rats during operant tasks for reward. Prog Brain Res 126:303-322.

Yi SJ, Johnson KM (1990) Chronic cocaine treatment impairs the regulation of synaptosomal 3H-DA release by D2 autoreceptors. Pharmacol Biochem Behav 36:457-461.

Zoltay G, Cooper JR (1994) Presynaptic modulation by dopamine and GABA opens a potassium channel in rat cortical, striatal and hippocampal synaptosomes via eicosanoids. Neurochem Int 25:345-348. 